\title{
Infected food handlers led to an outbreak of hepatitis A in Ernakulam district, Kerala, Southern India, 2016
}

\author{
Karishma Krishna Kurup ${ }^{a, *}$, P. Manickam ${ }^{a}$, Yogesh Gurav ${ }^{b}$ \\ ${ }^{a}$ ICMR-National Institute of Epidemiology, India \\ ${ }^{\mathrm{b}}$ ICMR-National Institute of Virology, India
}

\section{A R T I C L E I N F O}

\section{Keywords:}

Outbreak

Hepatitis A

Food handlers

Vaccination

\begin{abstract}
A B S T R A C T
Objective: Integrated Disease Surveillance Programme (IDSP) of Ernakulam district of Kerala, India received reports of a cluster of acute jaundice on 26th November 2016 at Panchayath A. We investigated to identify the agent, source and propose recommendations.

Method: We defined a probable case as acute onset of jaundice with or without malaise, anorexia, fever, dark urine among residents of Panchayath A, Ernakulam district, since 2nd week of November 2016.

Result: A total of 385 cases (Attack rate: 8/1000) and 3 deaths (Case fatality ratio: 0.8\%) were reported from 45th week of 2016 to 1 st week of 2017. The attack rate was highest among men (83\%) and those aged 16-30 years $(61 \%)$. The cases were clustered in ward 3 of the Panchayath, where a hotel was situated. Most casepatients interviewed (84\%) stated that they dined at that hotel. The index case was a construction worker who resided with hotel staff and subsequently reported illness. We confirmed HAV IgM in all specimens tested. HAV was associated with consumption of lemon juice $[\mathrm{OR}=17.1$; 95\% CI: 3.8-76.7; PAF $=61 \%$ ] and drinking water [OR: 15.3; 95\% CI: 3.7-63.2; PAF $=66 \%$ ] at the hotel.

Conclusion: Consumption of lime juice prepared by infected food handlers led to outbreak of hepatitis A. We recommended safe food preparation, drinking boiled water and super-chlorination of wells.
\end{abstract}

\section{Introduction}

Hepatitis A is an enterically transmitted viral disease belonging to genus Hepatovirus family Picornaevirae. ${ }^{1}$ More than a million cases occur worldwide annually and a high disease burden is reported in South East Asian region. ${ }^{2}$

India is hyperendemic for hepatitis A virus (HAV) with ${ }^{3,4}$ at least one outbreak reported from 23 states every year. States reporting the highest number of outbreaks to include Punjab, Uttarakhand, Gujarat, Maharashtra and Kerala. ${ }^{5}$ During 2011 to 2013, Kerala reported more than $20 \mathrm{HAV}$ outbreaks. ${ }^{12-14,21}$ The incubation period of hepatitis A lasts 15-50 days with symptoms of fever, malaise, loss of appetite, diarrhoea, nausea, abdominal discomfort, dark-colored urine and jaundice. Risk of transmission is high prior to the onset of jaundice since the viral concentration in the stool is at its peak during that period. ${ }^{6,7,8}$ Though the disease is self-limiting, symptoms can last for two months; in a few cases (10-15\%), it continues to six months. ${ }^{9,10}$ Consuming boiled water, water chlorination and good sanitation practices prevent disease transmission. Inactivated and attenuated hepatitis A vaccines are available and on completing dosage, it ensures immunity for $5-8$ years. ${ }^{11}$

On 25th November 2016, hepatitis A cases were reported to Integrated Disease Surveillance Programme (IDSP) office of Ernakulam district, from a private hospital in Panchayath A having a population of 45,981 (51\% male). On 29 November 2016, we investigated the outbreak to confirm the diagnosis and identify the source.

\section{Methods}

\subsection{Descriptive epidemiology}

We defined a case of probable hepatitis A as "acute onset of jaundice with or without malaise, anorexia, fever, dark urine among residents of Panchayath A, since the second week of November 2016". We actively searched for cases through door-to-door and through passive surveillance at public, private institutions and traditional healer clinics in the surrounding block panchayath. For each case-patient, we collected information on age, gender, place of residence and time of onset. We interviewed case-patients, key informants and construction workers to generate hypotheses about potential exposures and calculated attack

\footnotetext{
* Corresponding author. ICMR-National Institute of Epidemiology, Near Tamil Nadu Housing Board, Ayapakkam, Chennai-07, India.

E-mail addresses: doctorkarishma31@gmail.com (K.K. Kurup), manickam@nie.gov.in (P. Manickam), gurav.yk@gmail.com (Y. Gurav).
} 
rate by age and gender. We drew an epidemic curve for distribution of cases by time of onset and plotted cases by their residence in the Panchayath A.

\subsection{Analytical epidemiology}

Findings from the descriptive study resulted in generating a hypothesis which we tested using a case-control study. We defined case as that probable case with HAV specific IgM and we defined controls as those without hepatitis A disease. We collected information regarding socio-demographic characteristics and food items consumed using a standardized questionnaire. We compared cases with that of controls and calculated odds ratio (OR) with $95 \%$ confidence interval (CI). We calculated adjusted ORs and $95 \%$ CIs by age and gender using the Mantel-Haenszel method. We calculated the fraction of cases attributable to the risk factors in the population [Populated Attributable Fraction (PAF)] by multiplying the proportion of cases exposed by the attributable fraction among the exposed [(OR-1) divided by OR)]

\subsection{Laboratory investigations}

We collected blood specimens of case-patients and tested for HAV specific IgM using ELISA at the District public health laboratory. The team was conducting the outbreak investigation as a part of a public health emergency response, hence the procedure and aim of blood collection was well explained to the participant, however ethical clearance was not obtained a priori. ${ }^{30}$

\subsection{Environmental investigations}

We collected water specimen from the wells located in hotel premises and an ice factory that supplied ice to the hotel. The samples were tested for contamination by testing for the presence of fecal Escherichia coli. We interviewed and examined the construction workers and staff members from the hotel and ice factory. We conducted a sanitary inspection of the hotel premises and an ice factory.

\section{Results}

\subsection{Descriptive epidemiology}

We identified 385 cases in Panchayath A (Attack rate: 8 per 1000 population) and 3 deaths (Case fatality ratio: $0.8 \%$ ). We did not observe any recent changes in population or migration. We compared number of reported cases with that of surveillance data and ruled out any artefacts. The most common symptom was fever(95\%) followed by jaundice $(90 \%)$ and dark urine $(76 \%)$. The attack rate (Table 1) was highest among persons aged $16-30$ years $(61 \%)$. Women were less affected than men (17\% versus $83 \%)$. The patients have mainly sought

Table 1

Attack rate of hepatitis A by age and gender in Panchayath A of Kerala, India, 2016.

\begin{tabular}{lllll}
\hline Demographic characteristics & Cases & 2016 population & $\begin{array}{l}\text { Attack rate per } \\
100,000\end{array}$ \\
\hline Age (years) & $0-5$ & 1 & 3208 & 31 \\
& $6-15$ & 47 & 6703 & 701 \\
& $16-30$ & 236 & 9858 & 2393 \\
& $31-45$ & 92 & 10,762 & 854 \\
& $45-60$ & 11 & 9296 & 118 \\
& $>60$ & 2 & 6154 & 32 \\
\cline { 2 - 5 } Gender & Male & 321 & 23,200 & 1383 \\
& Female & 64 & 22,781 & 280 \\
\cline { 2 - 5 } Total & & 385 & 45,981 & 837 \\
\hline
\end{tabular}

treatment from traditional medical systems. The first case-patient developed the illness during the last week of October (Fig. 1). The outbreak peaked during week 47 and subsequently started declining by week 49. The shape of the curve suggested a point source outbreak. According to the spot map, cases clustered around ward 3 of the Panchayath, where the hotel was located. In-depth interviews with a subset of the case-patients indicated that most had dined at the hotel (84\%). The index case was a construction worker who resided with the food handlers in the hotel. Of the nine working at the hotel, three cooks, two service staff and the manager contracted the disease; all of them continued working in the hotel during the period of illness.

\subsection{Analytical epidemiology}

Review of the descriptive epidemiology led us to suspect the food item that was served at a particular hotel in Panchayath A to be associated with the spread of the infection. We recruited 22 cases and 27 controls for the case-control study. They differed by age and gender (Table 2). Compared with controls, cases were more likely to be exposed to drinking lemon juice $[\mathrm{OR}=17 ; 95 \% \mathrm{CI}$ : $4-77$; $\mathrm{PAF}=61 \%$ ] and drinking the served water [OR: $15 ; 95 \%$ CI: 4-63; PAF $=66 \%$ ] [Table 3].

\subsection{Laboratory investigations}

All the 15 blood specimens collected from the case patients tested positive for HAV specific IgM.

\subsection{Environmental investigations}

Wells are the main source of drinking water supply in the Panchayath A but there is a pipeline supply from the government water authority to one area within the Panchayath A. No cases were reported from this area. We collected 19 water specimens during surveillance week 49-51 of 2016 from the wells of the hotel, ice factory and nearby water bodies. Total coliform testing of these water samples were conducted in District Public health laboratory, Ernakulam to check the microbiological contamination of water. ${ }^{32}$ Testing of specimens confirmed E.coli in four specimens suggesting faecal contamination. However the water of the wells used at the ice factory and the hotel were contaminated with non fecal coliforms. Sanitary survey of the hotel suggested that the well in the hotel did not meet the objective criteria of a sanitary well. Based on the criteria the well was less than a metre away from a water canal, which was a common spot for waste disposal, the inner lining of the wall was made of mud allowing water seepage from the side and there was no cement cover over the well allowing a risk of contamination. Water from this well was used for cooking, washing and drinking requirements in the kitchen. The well was not chlorinated and there was a practice of consuming unboiled water. The well was located a meter away from the runoff to the village canal where frequent dumping of waste was reported by the residents.

We identified that the ice factory used both filtered and unfiltered water from a nearby well. Ice prepared from this factory was used for storage and sold for use during local functions. We checked for availability of purchase receipts to confirm the use of ice prepared at the ice factory in the concerned hotel and other local sites. However, such receipts were not maintained.

Our interview of construction workers who resided in the area led to the identification of the primary case. The primary case gave a history of hepatitis A in the family and a local hepatitis A outbreak in the area of residence during the last week of August, epi week 33, 2016. Following a probable exposure to hepatitis A affected family member, the patient worked at the hotel from 1 to 23 October 2016, (corresponding to epi week 38-42) and shared residence with staff members of the hotel. The patient identified as primary case developed symptoms on 23 October 2016 after which he returned to his residence. This 


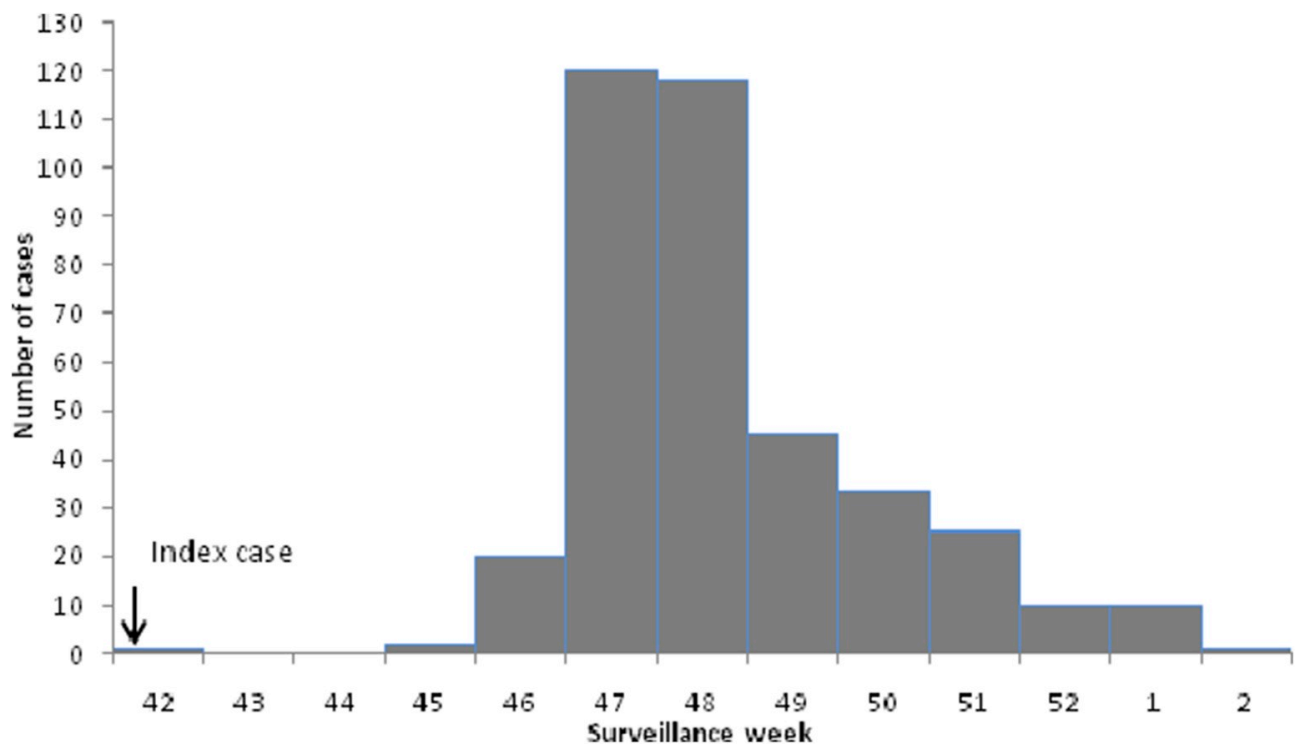

Fig. 1. Incidence of Hepatitis A by week of reporting; in Panchayath A, Ernakulum District, Kerala, India, $2016-2017$.

Table 2

Frequency of consumption of food items among Hepatitis A cases and controls, case control study, Kerala, India, 2016.

\begin{tabular}{|c|c|c|c|c|c|c|}
\hline \multirow[t]{2}{*}{ Food items taken } & \multicolumn{2}{|c|}{ Cases $(n=22)$} & \multicolumn{2}{|c|}{ Controls $(n=27)$} & \multirow[t]{2}{*}{ Odds ratio } & \multirow[t]{2}{*}{ 95\% Confidence Interval } \\
\hline & Number & $\%$ & Number & $\%$ & & \\
\hline Drinking water & 16 & 73 & 4 & 15 & 15.3 & $(3.7-63.2)$ \\
\hline Lemon juice & 15 & 68 & 3 & 11 & 17.1 & $(3.8-76.7)$ \\
\hline Beef fry & 2 & 9 & 2 & 7 & 2.1 & $(0.2-9.7)$ \\
\hline Milk shake & 0 & 0 & 2 & 7 & 1.1 & $(0.9-1.2)$ \\
\hline Fried rice & 2 & 9 & 1 & 4 & 2.6 & $(0.2-30.7)$ \\
\hline Grilled chicken & 2 & 9 & 3 & 11 & 0.8 & $(0.1-5.3)$ \\
\hline Kuboos/flat bread & 7 & 31 & 5 & 19 & 2.1 & $(0.5-7.7)$ \\
\hline Biryani & 6 & 27 & 10 & 37 & 0.6 & $(0.2-2.1)$ \\
\hline Chicken curry & 1 & 5 & 1 & 4 & 1.2 & $(0.1-20.9)$ \\
\hline Chapatti/Indian bread & 3 & 14 & 1 & 4 & 4.1 & $(0.4-42.6)$ \\
\hline Vegetable Salad & 9 & 41 & 10 & 37 & 1.2 & $(0.4-3.7)$ \\
\hline Mayonnaise & 7 & 32 & 10 & 37 & 0.8 & $(0.2-2.6)$ \\
\hline Shawarma/Grilled chicken & 4 & 18 & 2 & 7 & 2.8 & $(0.5-16.8)$ \\
\hline Alfam/barbeque chicken & 8 & 36 & 12 & 44 & 0.7 & $(0.2-2.3)$ \\
\hline
\end{tabular}

Table 3

Crude and Adjusted estimates of OR for suspected food items.

\begin{tabular}{|c|c|c|c|c|c|c|}
\hline Food Item & Crude OR & $95 \% \mathrm{CI}$ & Adjusted OR by age & $95 \% \mathrm{CI}$ & Adjusted OR by gender & $95 \% \mathrm{CI}$ \\
\hline Lemon juice & 17.14 & $3.8-76.7$ & 15.8 & $3.4-73.8$ & 10.3 & $2.3-45$ \\
\hline Drinking water & 15.3 & $3.7-63.2$ & 13.7 & $3.2-58.5$ & 9.6 & $2.1-43.6$ \\
\hline
\end{tabular}

information was used to develop the case definition for epidemiological purpose. According to the staff members the hotel was inaugurated on 24 October and all the staff members were living together in the room within the hotel premises provided by the owner during this period. They complained of overcrowding and lack of cleanliness during their stay and mentioned about the practice of drinking unboiled water daily from the hotel.

Further, Investigator revealed that that lukewarm water was routinely served to the customers. Ice purchased from a local factory was used for the first week and subsequently suspected contaminated well water was used. As part of personal protection they reported the use of hairnets while handling food. Food samples could not be tested for contamination with HAV as it was not available at the time of visit.

\section{Discussion}

We confirmed one of the largest outbreak of hepatitis A in Panchayath A, reported in the state of Kerala. The attack rate was highest among men in the economically productive age group and most of them had dined at a hotel. We identified that consumption of lemon juice and drinking water served at the hotel as risk factors among cases as compared to controls.

The attack rate of HAV was higher among adults and less among children. This could be due to the fact that in Kerala, the overall improved hygienic conditions and socio-economic development, could have reduced the risk of HAV infection in childhood. ${ }^{22}$ Most of the time, Hepatitis A infection is asymptomatic among children. The severity of hepatitis A increases with age and infections in adults are often symptomatic. Hence, an occurrence of HAV in any such population may lead to outbreaks as reported from other parts of India. ${ }^{23,24}$ As stated earlier, 
Kerala has indeed experienced several HAV outbreaks in the recent past with fatality among adults. ${ }^{21,25}$

In the current investigation, we argue that hand hygiene could have played a significant role in the transmission of HAV. Several published studies documented the higher HAV transmissibility potential of soiled and unwashed or disinfected hands. ${ }^{18}$ However, the minimum infectious dose of HAV needed for resulting in disease remains unknown. ${ }^{19,20}$

Based on the evidence, the most probable source of contamination of the food prepared at a hotel was through poor hand hygiene of the food handlers. ${ }^{5,15-17}$

Though the main risk factors for the disease transmission were lemon juice and water that were served at the restaurant, these routes of transmission existed due to a combination of factors such as overcrowding, drinking unprotected water and lack of personal hygiene among hotel food handlers and that of probable use of contaminated ice could have facilitated this transmission. Further evidence also suggests that little over $60 \%$ of the cases in the community could be explained by drinking lemon juice or the served water.

Our investigation suffers from the most common difficulty faced while investigating the root cause of the HAV transmission everywhere. For instance, recent study of surveillance data from India's IDSP suggested that even in a setting like Kerala state with strong public health system, the causes of the many hepatitis A outbreaks in the last five years were attributed to the poor status of water quality. ${ }^{21}$ Hence, outbreaks of food-borne/food handlers are generally under-investigated or under-reported in Kerala. Almost one fifth of the HAV outbreaks in the United States during 1993-2001 were attributed to food handlers. ${ }^{17}$ However poor reporting and publication of HAV outbreaks due to food handlers had been documented in a review from Canada. ${ }^{26}$ This was similar with the pattern we observed in this reported outbreak. In this context, evidence for food-borne transmission from our investigation suggests the importance of implementing public health measures at food establishments to reduce the transmission hepatitis A. World Health Organization has highlighted the importance of vaccination with Hepatitis A. Many countries have documented marked reduction in HAV incidence following mass vaccination. But vaccination for HAV in the Indian context is not considered due to hyperendemic status of the disease and life-long immunity offered to children as a result of subclinical infection. ${ }^{21}$ Looking into the outbreak data for the last 5 years, in the state of Kerala, the shift in age of hepatitis A infection has been documented. ${ }^{21}$ Thus raising the debate of HAV vaccination. In addition, there also exists a lack of studies that has looked on costeffectiveness of HAV vaccination as compared to the out of pocket expenditure in a large outbreak. ${ }^{21}$

A report on a 2001 hepatitis A outbreak due to food handler transmission from a restaurant in Massachusetts evaluated the societal costs to be as high as 800,000 US\$, which was paid by the public health agency. ${ }^{27}$ In addition a study that was done later that looked into the economic burden due to food borne illness in the United States, estimated the cost of a hepatitis A case in 2010 to be $37,073 \$$ (95\% CI 9033-71,112) and posed a high economic burden to the country itself along with other similar illness. ${ }^{28}$ In a country like India there are very limited studies that have looked into the economic implications of food borne transmission of diseases. Looking into the studies conducted in high income countries and previous outbreak reports of hepatitis A in India we can estimate that the financial burden Hepatitis A poses for the public health agency and the public would be staggering. ${ }^{21}$

It is worth referring to the local cultural practices that might naturally promote the prevention of diseases. In Kerala, one is often greeted in a household or a hotel with drinking water, which may be hot or lukewarm water. According to reports, such practice is prevalent in $65 \%$ of urban and $49 \%$ of rural settings. ${ }^{31}$ In the current episode, we were informed by participants that lukewarm water was served at the hotel. However, further enquiries with the hotel staff identified that there was mixing of the boiled hot water before serving the customers.
Therefore, such information adds to the importance of the role of cultural practices in preventing such disastrous consequences.

Our study has few limitations. While wells were reported to be the main source of drinking water, we could not collect well water samples prior to chlorination. We identified most of them with fecal contamination and hence, reflected on poor quality of chlorination methods. We would also like to point to previous published evidence that shows the molecular existence of HAV in environment is longer than fecal coliform bacteria. Hence the wells that showed a non fecal contamination as seen in the wells of the hotel and ice factory could also be HAV contaminated but we were unable to elicit this due to the lack of molecular investigation in our study. ${ }^{29}$ There was a lack of information about the other sites where ice from ice factory had been supplied, apart from the hotel, this hampered our investigation as we were unable to ascertain any other focal points of HAV infection. Further we could not obtain food samples for testing. However, the prevailing circumstances as per the interviews and population attributable risk suggest that substantial transmission could be explained through the identified sources.

On the basis of our findings, we conclude that the HAV outbreak in Panchayath A could be due to food and water-borne. We recommend avoidance of consuming unboiled water from sources such as well water.

\section{Financial support}

This research received no specific grant from any funding agency, commercial or not-for-profit sectors.

\section{Conflicts of interest}

None.

\section{Acknowledgements}

I would like to thank the director Dr Manoj Murhekar, Scientist G, National Institute of Epidemiology (NIE), ICMR, Chennai for support in conducting my outbreak investigation, Dr. Tarun B, Scientist E, Course coordinator, Masters in Public Health Program, NIE, Chennai who provided me valuable comments and support. I am also thankful to the District NRHM Officer, District Medical Officer, District Surveillance officer, District Epidemiologist and Health inspector, Supervisors and JPHN of Ernakulam district who provided assistance to the investigation but who do not qualify for authorship.

\section{Appendix A. Supplementary data}

Supplementary data to this article can be found online at https:// doi.org/10.1016/j.cegh.2019.08.001.

\section{References}

1. Pal S, et al. An outbreak of hepatitis A virus among children in a flood rescue camp: a post-disaster catastrophe. Indian J Med Microbiol. 2016 Apr 1;34(2):233.

2. Kim KA, Lee A, Ki M, Jeong SH. Nationwide seropositivity of hepatitis a in Republic of Korea from 2005 to 2014, before and after the outbreak peak in 2009. PLoS One. 2017;12(1): 0170432.

3. Sowmyanarayanan TV, et al. Investigation of a hepatitis A outbreak in children in an urban slum in Vellore, Tamil Nadu, using geographic information systems. Indian $J$ Med Res. 2008 Jul;128(1):32-37.

4. Batra $Y$, et al. Vaccination against hepatitis A virus may not be required for schoolchildren in northern India: results of a seroepidemiological survey. Bull World Health Organ. 2002;80(9):728-731.

5. Kumar T, et al. Viral hepatitis surveillance - India, 2011-2013. MMWR (Morb Mortal Wkly Rep). 2015;64(28):758-762

6. Wiseman R, Weil LM, Lozano C, et al. Notes from the field. health care -associated hepatitis A outbreak-Texas, 2015. Morb Mortal Wkly Rep. 2016;65:425-426.

7. Hepatitis a questions and answers for health professionals | division of viral hepatitis | CDC. https://www.cdc.gov/hepatitis/hav/havfaq.htm\#A3, Accessed date: 6 March 2017. 
8. Beller M. Hepatitis A outbreak in Anchorage, Alaska, traced to ice slush beverages West J Med. 1992 Jun;156(6):624-627.

9. Rowe LS, Tanner K, Gregory EJ. Hepatitis A outbreak epidemiologically linked to a food handler in Melbourne. Vic Commun Dis Intell. 2009;33:47-49.

10. Acheson D, Fiore AE. Hepatitis a transmitted by food. Clin Infect Dis. 2004 Mar 1;38(5):705-715.

11. WHO | hepatitis A. http://www.who.int/mediacentre/factsheets/fs328/en/, Accessed date: 7 March 2017.

12. Beebeejaun $\mathrm{K}$, et al. Outbreak of hepatitis A associated with men who have sex with men (MSM), England, July 2016 to January 2017. Euro Surveill: Bullet Eur Sur les Maladies Transmissibles Eur Commun Dis Bullet. 2017 Feb 2;22(5).

13. Yu P, et al. Epidemiological investigation of an outbreak of hepatitis A in rural China. Int J Infect Dis. 2015 Apr;33:191-195.

14. Acharya SK. This is hepatitis: know it, confront it. Indian J Med Res. $2013 \mathrm{Jul}$ $1 ; 138(1): 8$.

15. Raveendran $\mathrm{S}$, et al. Investigation of an outbreak of hepatitis a in a coastal area, Kerala, southern India. J Prim Care Commun Health. 2016 Oct 1;7(4):288-290.

16. Rakesh $\mathrm{P}$, et al. Investigating a community-wide outbreak of hepatitis a in India. $J$ Glob Infect Dis. 2014;6(2):59-64.

17. Sharapov UM, et al. Hepatitis a infections among food handlers in the United States, 1993-2011. Public Health Rep. 2016;131(1):26-29.

18. Akabanda F, Hlortsi EH, Owusu Kwarteng J. Food safety knowledge, attitudes and practices of institutional food-handlers in Ghana. BMC Public Health. 2017 Jan 6;17(1):40

19. Bidawid S, Farber JM, Sattar SA. Contamination of foods by food handlers: experiments on hepatitis a virus transfer to food and its interruption. Appl Environ Microbio $2000 \mathrm{Jul} ; 66(7): 2759-2763$.

20. Heywood P, et al. A community outbreak of travel-acquired Hepatitis A transmitted by an infected food handler. Archiv- Can Commun Dis Rep. 2007 Nov;33(12):16-21. 21. Sreelakshmi Mohandas K. 84 outbreaks of Hepatitis A in last five years in Kerala State-are we resigning to fate? Natl J Res Commun Med. 2017 Jul 3;6(3):267-270.

22. Acharya SK, et al. Viral hepatitis in India. NMJI (Natl Med J India). 2006;19:203-217.

23. Chobe LP, Arankalle VA. Investigation of a hepatitis A outbreak from shimla Himachal Pradesh. Indian J Med Res. 2009;130:179-184.

24. Sharma AK, et al. Upsurge in vaccine preventable hepatitis A virus infection in adult patients from a tertiary care hospital of North India. Int J Infect Dis. 2016;45:457.

25. Zachariah SM, et al. Investigation of hepatitis a outbreak in palakkad district. Int $J$ Commun Med Publ Health. 2017;4:4125-41230.26.

26. Tricco AC, et al. A review of interventions triggered by hepatitis A infected foodhandlers in Canada. BMC Health Serv Res. 2006 Dec 8;6(1):157.

27. Foodborne transmission of hepatitis A-Massachusetts, 2001. MMWR (Morb Mortal Wkly Rep). 2003;52(24):565-567.

28. Scharff RL. Economic burden from health losses due to foodborne illness in the United States. J Food Prot. 2012;75(1):123-131.

29. Serres GD, Cromeans TL, Levesque B, et al. Molecular confirmation of hepatitis a virus from well water: epidemiology and public health implications. J Infect Dis. 1999 Jan 1;179(1):37-43.

30. ICMR. National Ethical Guidelines for Biomedical and Health Research Involving Human Participants. [Internet]. 2017; 2017. Available from: https://www.icmr.nic.in/sites/ default/files/guidelines/ICMR_Ethical_Guidelines_2017.pdf.

31. Payyappallimana U. Traditional Medicine in Health System Development: A Case Study of Kerala State, India. 2010; 2010.

32. WHO UNEP. Water Quality Monitoring - A Practical Guide to the Design and Implementation of Freshwater Quality Studies and Monitoring Programmes. [Internet]. 1996; 1996 Availablefrom: https://www.who.int/water_sanitation_health/ resourcesquality/wqmchap10.pdf. 